Journal of Thermal Engineering, Vol.7, No.4, pp.890-903,May, 2021

Yildiz Technical University Press, Istanbul, Turkey

\title{
A SYSTEMATIC GRAPHICAL METHOD FOR SYNTHESIS OF HEAT EXCHANGER NETWORKS
}

\author{
Mohammad A. Al-Mayyahia ${ }^{1 *}$, Mohammad N. Fares², Nabeel K. Abbood ${ }^{1}$
}

\begin{abstract}
Heat exchanger networks (HENs) play a significant role in the energy conservation of any process industry. The HENs are used to maximize heat recovery by exchanging heat between hot and cold process streams. Therefore, the optimum design of HENs is extremely important to reach the maximum efficiency of energy systems. Many graphical methods have been developed during the last four decades for synthesizing of heat exchanger networks (HENs). However, most of these methods have only been evaluated for retrofitting design of HENs. In the grassroots design situation, these methods are often complicated and tedious. This paper introduces a new and simple graphical approach for HEN grassroots design. The new approach based on a single graph called Supply-Target Diagram (STD). The ST-D is formulated by plotting supply temperatures versus target temperatures of streams. Streams matching can easily be applied in the ST-D and splitting of streams is clearly visualized and evaluated. A case study is used to illustrate the application of the new graphical method for grassroots design of HENs.
\end{abstract}

Keywords: Pinch Analysis, Energy Integration, Graphical Approach, Supply-Target Diagram, Heat Exchanger Network

\section{INTRODUCTION}

The global demand for energy has been considerably increasing due to the continuous growth in the global economic. This increase in the energy consumption and its environmental, economic and societal effects has created escalating global concern [1]. This concern has been reflected in huge research on the energy efficiency of various sectors including commercial, residential, transportation and industrial [2-6]. The latter contributes in nearly $38 \%$ of global energy consumption. Therefore, improving energy efficiency of various industries could significantly reduce global energy demand [7]. Recently, the efficiency of energy use in energy-intensive industries has become the common interest of many researchers [5]. For the sake of efficient grassroots and retrofitting design of energy systems, many graphical and mathematical techniques have been developed [8-28]. Process Integration, which was introduced by Linnhoff and Flower, 1978, has been used extensively on increasing energy efficiency of processing systems [9]. The process integration technique, also called pinch analysis, was first introduced to analyze energy flows in process heat exchanger networks. Pinch analysis is based on the second law of thermodynamics which states that heat can only flow from higher temperatures (sources) to lower temperatures (sinks) [15]. Pinch analysis uses graphics and tables to provide a good overview of processes to the designer. The most popular graphical and tabular tools are Composite curve (CC), grand composite curve (GCC), Problem Table Algorithms, and Grid diagram. The Composite Curve (CC) is formulated by plotting temperatures versus enthalpies of process streams to identify utilities targets and pinch temperature. Grand composite curve (GCC) is produced by plotting the net heat-flow of a process at different temperatures. The GCC helps in identifying regions where external heating and cooling utilities are required. Problem Table is used for algebraically setting heating and cooling targets [15].

The typical grid diagram (GD) was introduced by Linhoff and flower (1978) for the grassroots design of heat exchanger networks (HENs) [9]. The GD is formulated by presenting streams as horizontal arrows. Each heat exchanger is represented in the GD by a vertical line connecting a hot and cold stream. The GD is a very common graphical tool for both grassroots and retrofitting design of HENs. However, visualization of important design

This paper was recommended for publication in revised form by Regional Editor

${ }^{1}$ Department of Chemical and Petroleum Refining Engineering, Basrah University for Oil and Gas, Basrah, IRAQ

${ }^{2}$ Department of Chemical Engineering, Basrah University, Basrah, IRAQ

${ }^{*} E$-mail address: moh1973may@gmail.com

Orcid id: 0000-0003-3773-5505, 0000-0003-3089-7026, 0000-0002-9828-4982

Manuscript Received 10 May 2019, Accepted 11 September 2019 
parameters such as streams' temperature intervals and enthalpies are not straightforward in the GD [16]. Furthermore, splitting and matching feasibility of streams are not easy evaluated.

Since GDs was introduced, many graphical methods have been developed for synthesizing and retrofitting of HENs. Retrofit Thermodynamic Diagram (RTD) was introduced by Lakshmanan and Bañares-Alcántara (1996) using both the driving forces and heat contents of streams to analyze and retrofit existing HENs [17]. Another graphical technique based on several curves was introduced by Nordman and Berntsson (2001) to determine the investment cost associated with the changes in heating and cooling of HEN [18]. Osman et al. (2009) proposed a retrofitting graphical method based on the path analysis approaches to increase the heat transfer area without any structural changes on the existing HEN [19]. Wan Alwi and Manan (2010) developed a graphical method based on the stream temperature versus enthalpy plot (STEP) [20]. The STEP is used to target and design HENs simultaneously. Grid Diagram Table (GDT) was introduced by Abbood et al. (2012) for HENs retrofitting and utilities targeting [21]. The GDT combines graphical and numerical tools into a single diagram. Gaddallad et al. (2016) developed the temperature driving force (TDF) method for retrofitting of existing heat exchanger networks (HENs) [17]. Yee Qing Lai et. al. used the STEP technique for analyzing and retrofitting of existing HENs [17]. Recently, Yeo et. al. (2017) extended the application of STEP method to involve phase changes [24]. Recently, a new graphical method uses Supply-Target Diagram (ST-D) was introduced by Al-Mayyahi et al. (2019) for retrofitting design of heat exchanger network [25].

However, even though these graphical methods offer good visualization techniques for HENs design, they have some limitations such as the points listed below:

- The majority of the graphical methods were presented as retrofitting design techniques of HENs.

- Most of the graphical methods that developed for grassroots design of HENs use cumbersome construction processes.

- Others such as GDs are sometimes tedious and hard to follow due to the lack of visualization regarding temperatures intervals of streams and enthalpies.

This paper presents a new and simple graphical approach for HEN grassroots design. The significance of the new method is its simplicity and comprehensibility. The approach based on a single graph called Supply-Target Diagram (ST-D). The ST-D is formulated by simply plotting supply temperatures versus target temperatures of streams. Streams matching can easily be applied in the ST-D and stream splitting is clearly visualized and evaluated.

In the following sections of the paper, background information on the new graphical technique will be given and step by step construction procedure discussed. Then, a case study is used to illustrate the application of the new graphical method for grassroots design of HENs. In order to validate the new graphical technique, the results will be compared with the grid diagram representation. Finally, a brief review of the paper and the significance of the new technique will be concluded.

\section{METHODOLOGY}

This section describes principles of the new graphical method for HENs representation. An illustrative example will be used next to discuss the graphical technique.

\section{Supply-Target Diagram (ST-D)}

The new graphical method uses a single diagram called supply-target diagram (ST-D) for the grassroots design of HENs. The ST-D is produced by plotting supply temperatures versus target temperatures of streams on the Y-axis and X-axis respectively. Then, streams matching can be directly done in the ST-D and matching constraints like cross-pinch and temperature feasibility can be easily observed. This makes the ST-D a powerful tool for HENs representation for new designs.

\section{Representation of a stream on ST-D}

Supply-target diagram can be used to represent process and utility streams as follows:

Consider a hot stream with supply and target temperatures equal to $\mathrm{T}_{\mathrm{SH}}$ and $\mathrm{T}_{\mathrm{TH}}$ respectively, and a cold stream with supply and target temperatures of $\mathrm{T}_{\mathrm{SC}}$ and $\mathrm{T}_{\mathrm{TC}}$ respectively, [3],

Then, 


$$
Q_{H}=C P_{H}\left(T_{T H}-T_{S H}\right)
$$

and,

$$
\mathrm{Q}_{\mathrm{c}}=\mathrm{CP}_{\mathrm{H}}\left(\mathrm{T}_{\mathrm{TC}}-\mathrm{T}_{\mathrm{SC}}\right)
$$

Where; $\mathrm{Q}_{\mathrm{H}}$ is the heat load of the hot stream, $\mathrm{C}_{\mathrm{PH}}$ is the heat capacity of the hot stream. $\mathrm{Q}_{\mathrm{C}}$ is the heat load of the cold stream, $\mathrm{C}_{\mathrm{PC}}$ is the heat capacity of the cold stream, see Figure 1.

From equation (1) and (2) we can get

$$
T_{S H}=\left(\frac{Q_{H}}{C P}\right)+\mathrm{T}_{\mathrm{TH}}
$$

and,

$$
\mathrm{T}_{\mathrm{SC}}=\left(\frac{\mathrm{Q}_{\mathrm{C}}}{\mathrm{CP}_{\mathrm{C}}}\right)+\mathrm{T}_{\mathrm{TC}}
$$

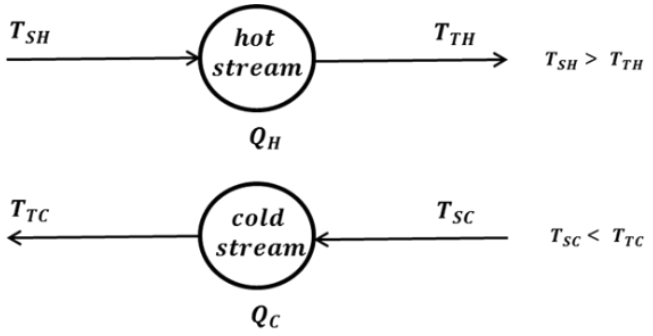

Figure 1. Hot and cold streams

Hot and cold streams can be represented on the ST-D using their supply $\left(\mathrm{T}_{\mathrm{S}}\right)$ and target $\left(\mathrm{T}_{\mathrm{T}}\right)$ temperatures as Y-coordinate and X-coordinate respectively, see Figure 2.

It can be seen from Figure 2 that when drawing a line parallel to the main diagonal line starting from hot or cold streams, the line intercepts $y$-axis or $x$-axis at values equal to $\left(\frac{Q_{H}}{\mathrm{CP}_{H}}\right)$ for hot stream and $\left(\frac{Q_{C}}{\mathrm{CP}_{C}}\right)$ for cold streams. Alternatively, values of $\left(\frac{\mathrm{Q}_{\mathrm{H}}}{\mathrm{CP}_{\mathrm{H}}}\right)$ and $\left(\frac{\mathrm{Q}_{\mathrm{C}}}{\mathrm{CP}_{\mathrm{C}}}\right)$ can be read from the vertical distance between the hot and cold streams and the diagonal line respectively, as it shown in Figure 2. Interestingly, the ST-D shows that all hot streams are represented above the main diagonal line whereas cold streams are located below this line.

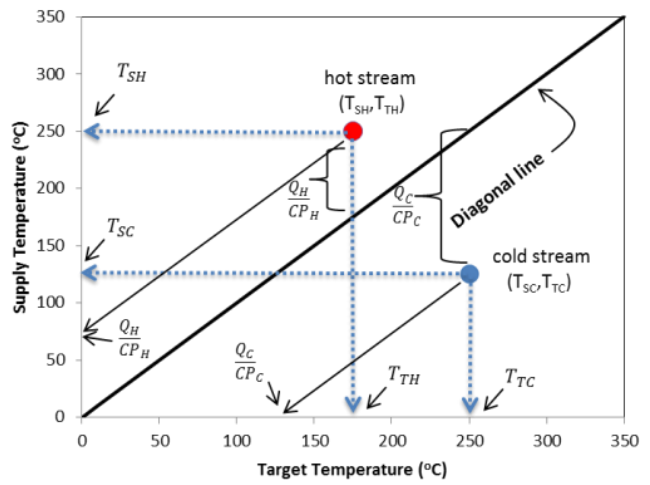

Figure 2. Representation of hot and cold streams on ST-D 


\section{Stepwise cooling process of a hot stream}

ST-D can be easily used to represent a process of cooling a hot stream in a series of heat exchangers. The overall cooling duty required by a stream is the summation of its all individual cooling processes as it explained by Equation 5. Figure 3 shows a three stages process of cooling a hot stream in a train of heat exchangers. It can be seen that:

$$
\frac{Q_{H}}{C P_{H}}=\frac{Q_{H 1}}{C P_{H}}+\frac{Q_{H 2}}{C P_{H}}+\frac{Q_{H 3}}{C P_{H}}
$$

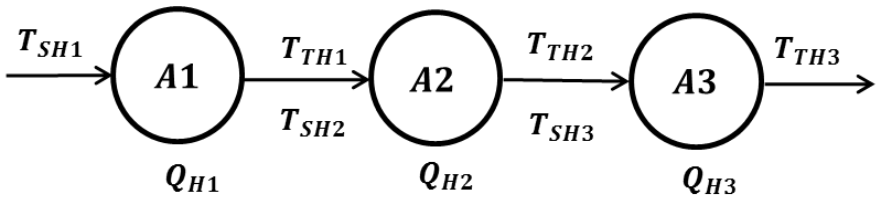

Figure 3. Stepwise cooling process of a hot stream

As shown in Figure 4, the stepwise cooling process can be represented on the ST-D following below steps:

- Stage 1 (A1) is the intercept between the horizontal line starting from $\mathrm{T}_{\mathrm{SH}}$ and a diagonal line starting from the value of $\mathrm{Q}_{\mathrm{H} 1} / \mathrm{C}_{\mathrm{PH}}$ on the Y-axis. Alternatively, the vertical distance between $\mathrm{A} 1$ and the diagonal line equal to $\left(\mathrm{Q}_{\mathrm{H} 1} / \mathrm{C}_{\mathrm{PH}}\right)$.

- The intercept of a vertical line from $\mathrm{A} 1$ with the main diagonal line gives $\mathrm{T}_{\mathrm{SH} 2}$.

- Stage 2 (A2) is the intercept between the horizontal line of $\mathrm{T}_{\mathrm{SH} 2}$ and a diagonal line starting from the value of $\mathrm{Q}_{\mathrm{H} 2} / \mathrm{C}_{\mathrm{PH}}$ on the Y-axis. Alternatively, the vertical distance between $\mathrm{A} 2$ and the diagonal line equal to $\left(\mathrm{Q}_{\mathrm{H} 2} / \mathrm{C}_{\mathrm{PH}}\right)$.

- The intercept of a vertical line from A2 with the main diagonal line gives $\mathrm{T}_{\mathrm{SH} 3}$.

- Stage 3 (A3) is the intercept between the horizontal line of $\mathrm{T}_{\mathrm{SH} 3}$ and a diagonal line starting from the value of $\mathrm{Q}_{\mathrm{H} 3} / \mathrm{C}_{\mathrm{PH}}$ on the Y-axis. Alternatively, the vertical distance between $\mathrm{A} 3$ and the diagonal line equal to $\left(\mathrm{Q}_{\mathrm{H} 3} / \mathrm{C}_{\mathrm{PH}}\right)$.

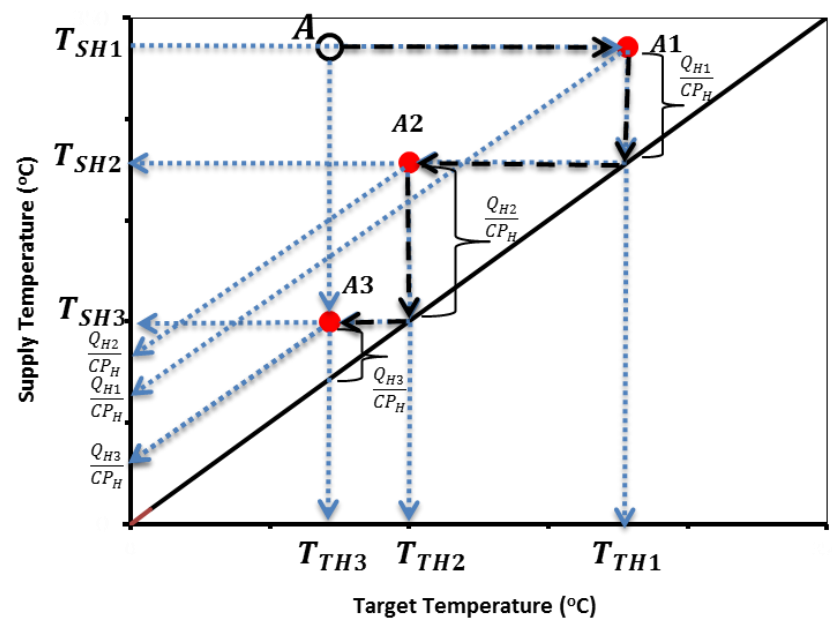

Figure 4. Stepwise cooling process of a hot stream on ST-D

\section{Stepwise heating process of a cold stream}

Similarly, the cold stream stepwise heating process can be represented by ST-D. The overall heating duty required by a stream is the summation of its all individual heating processes as it explained by Equation 6 . Figure 5 shows cooling a hot stream in a train of heat exchangers. It can be seen that:

$$
\frac{Q_{C}}{C P_{C}}=\frac{Q_{C 1}}{C P_{C}}+\frac{Q_{C 2}}{C P_{C}}+\frac{Q_{C 3}}{C P_{C}}
$$




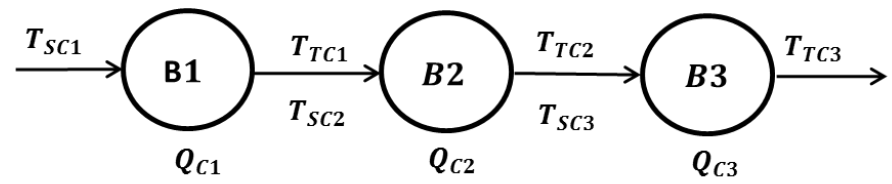

Figure 5. Stepwise heating of a cold stream

As it shown from Figure 6, the stepwise heating process can be represented by the ST-D following below steps:

- Stage 1 (B1) is the intercept between the horizontal line starting from $\mathrm{T}_{\mathrm{SC} 1}$ and a diagonal line starting from a value of $\mathrm{Q}_{\mathrm{Cl}} / \mathrm{CP}_{\mathrm{C}}$ on the $\mathrm{X}$-axis. Alternatively, the vertical distance between $\mathrm{B} 1$ and the diagonal line equal to $\left(\mathrm{Q}_{\mathrm{C} 1} / \mathrm{CP}_{\mathrm{C}}\right)$.

- The intercept of a vertical line from B1 with the main diagonal line gives $\mathrm{T}_{\mathrm{SC} 2}$.

- Stage 2 (B2) is the intercept between the horizontal line of $\mathrm{T}_{\mathrm{SC} 2}$ and a diagonal line starting from a value of $\mathrm{Q}_{\mathrm{C} 2} / \mathrm{CP}_{\mathrm{C}}$ on the $\mathrm{X}$-axis. Alternatively, the vertical distance between $\mathrm{B} 2$ and the diagonal line equal to $\left(\mathrm{Q}_{\mathrm{C} 2} / \mathrm{CP}_{\mathrm{C}}\right)$.

- The intercept of a vertical line from $\mathrm{B} 2$ with the main diagonal line gives $\mathrm{T}_{\mathrm{SC} 3}$.

- Stage 3 (B3) is the intercept between the horizontal line of $\mathrm{T}_{\mathrm{SC} 3}$ and a diagonal line starting from a value of $\mathrm{Q}_{\mathrm{C} 3} / \mathrm{CP}_{\mathrm{C}}$ on the $\mathrm{X}$-axis. Alternatively, the vertical distance between $\mathrm{B} 3$ and the diagonal line equal to $\left(\mathrm{Q}_{\mathrm{C} 3} / \mathrm{CP}_{\mathrm{C}}\right)$.

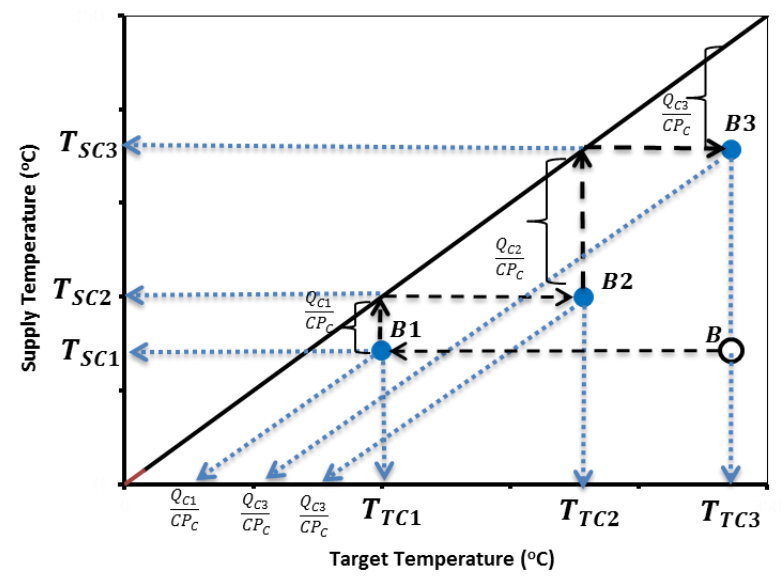

Figure 6. Stepwise heating of a cold stream on ST-D

\section{Using Supply-Target Diagram (ST-D) for HEN grassroots design}

The ST-D can be used to graphically design a new HEN based on principles of pinch analysis. The shifted temperature scale is used to generate the ST-D as shown in Figure 7. The ST-D is divided into 6 regions:

- Region 1: this region is for all hot streams that their supply and target temperatures are below the pinch temperature.

- Region 2: this region is for all hot streams that their supply temperatures are above the pinch temperature but their target temperatures are below the pinch temperature. Hot streams at this region are located cross pinch temperature.

- Region 3: this region is for all hot streams that their supply and target temperatures are above the pinch temperature.

- Region 4: this region is for all cold streams that their supply and target temperatures are above the pinch temperature.

- Region 5: this region is for all cold streams that their supply temperatures are below the pinch temperature but 
their target temperatures are above the pinch temperature. Cold streams at this region are located cross pinch temperature.

- Region 6: this region is for all cold streams that their supply and target temperatures are below the pinch temperature.

It should be noted that streams' phase changes can be represented in the ST-D as a point at the diagonal (same supply and target temperatures).

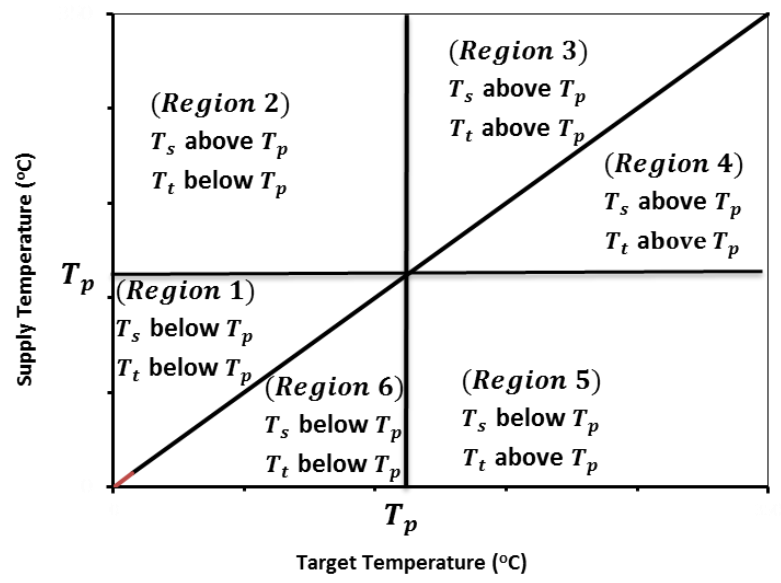

Figure 7. ST-D Regions

\section{Streams Matching Rules}

Each heat exchanger can be represented in the ST-D by a line connecting two streams, hot and cold streams. These two streams must have the same heat load and their temperature differences must not violate minimum temperature approach. In order to minimize utilities consumption and meet minimum energy targets, heat exchanger must not be matched across the pinch line. For the purpose of illustration, Figure 8 shows seven streams, two hot and five cold. It can be seen that:

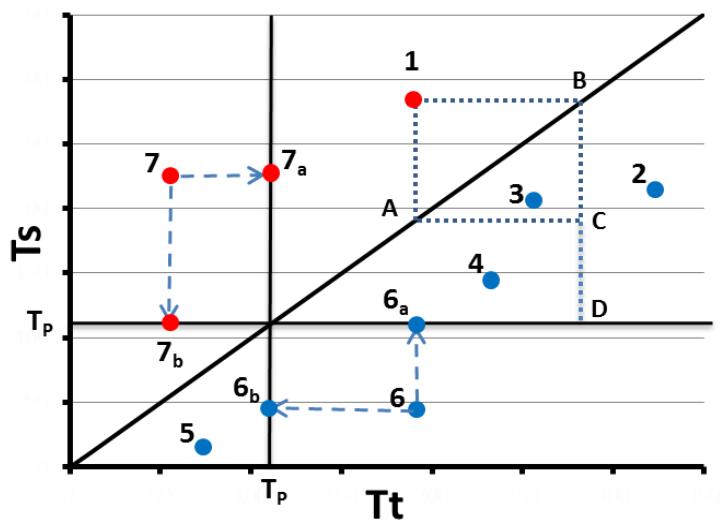

Figure 8. Stream matching rules

1. The hot stream 1 cannot be matched to any cold stream located to the right of the dotted line BD (such as stream 2). Matching hot stream 1 to cold stream 2 violates the minimum temperature approach, i.e. supply and target temperatures of the cold stream 2 is higher than target and supply temperatures of the hot stream 1 respectively.

2. Similarly, the hot stream 1 cannot be matched to any cold stream located above the dotted line AC (such as stream 3). Matching hot stream 1 to cold stream 3 violates the minimum temperature approach, i.e. supply temperature of cold stream 3 is higher than target temperature of the hot stream 1. 
3. The hot stream 1 can be matched to any cold stream, with same heat load, located below the dashed line AC, as shown in Figure 8 due to the minimum temperature satisfaction at both ends of any potential heat exchanger.

4. Both cold stream 6 and hot stream 7 are located cross pinch temperature, Tp. Therefore, they have to be split into two parts, below and above pinch point, (6a and 7a) and (6b and 7b) respectively, as shown in Figure 8.

\section{Algorithm of grassroots HEN design}

The grassroots design of HEN will be achieved by applying the new graphical methodology presented in Figure 9. Heat exchangers are formulated by following rules of streams matching mentioned in the later section. The HEN for streams above pinch is design first, and then HEN below pinch is formulated.

\section{CASE STUDY}

An existing HEN given by Asante and Zhu is considered as a case study for the purpose of illustration of the new graphical approach [26]. The HEN consists of five streams, four hot and one cold. Table 1 shows streams data of the HEN. The minimum temperature difference of $10{ }^{\circ} \mathrm{C}$ is considered in this case study. The application of pinch analysis principles shows that hot and cold energy targets are 125 and $15 \mathrm{MW}$ respectively and the pinch temperature is $145^{\circ} \mathrm{C}[26]$.

The new graphical method will be used to design a HEN with maximum heat recovery, following the grassroots design algorithm presented in Figure 9.

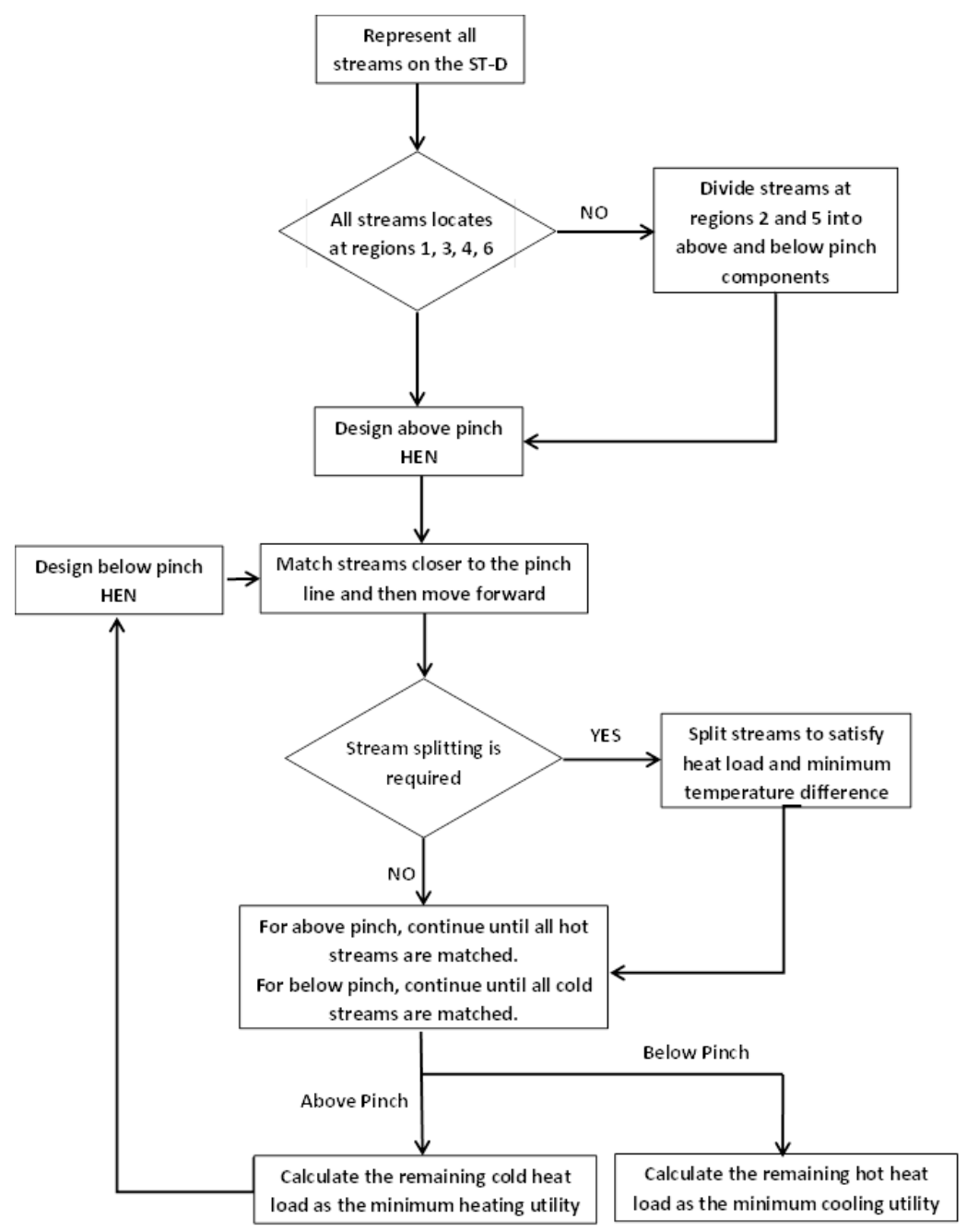

Figure 9. HEN grassroots design algorithm 
Table 1. Streams Data [26]

\begin{tabular}{|c|c|c|c|}
\hline Stream & Ts $\left({ }^{\circ} \mathrm{C}\right)$ & $\mathrm{T}_{\mathrm{t}}\left({ }^{\circ} \mathrm{C}\right)$ & $\mathrm{Q}(\mathrm{MW})$ \\
\hline 1 & 160 & 120 & 20 \\
\hline 2 & 200 & 160 & 20 \\
\hline 3 & 150 & 120 & 140 \\
\hline 4 & 200 & 130 & 70 \\
\hline 5 & 100 & 190 & 360 \\
\hline
\end{tabular}

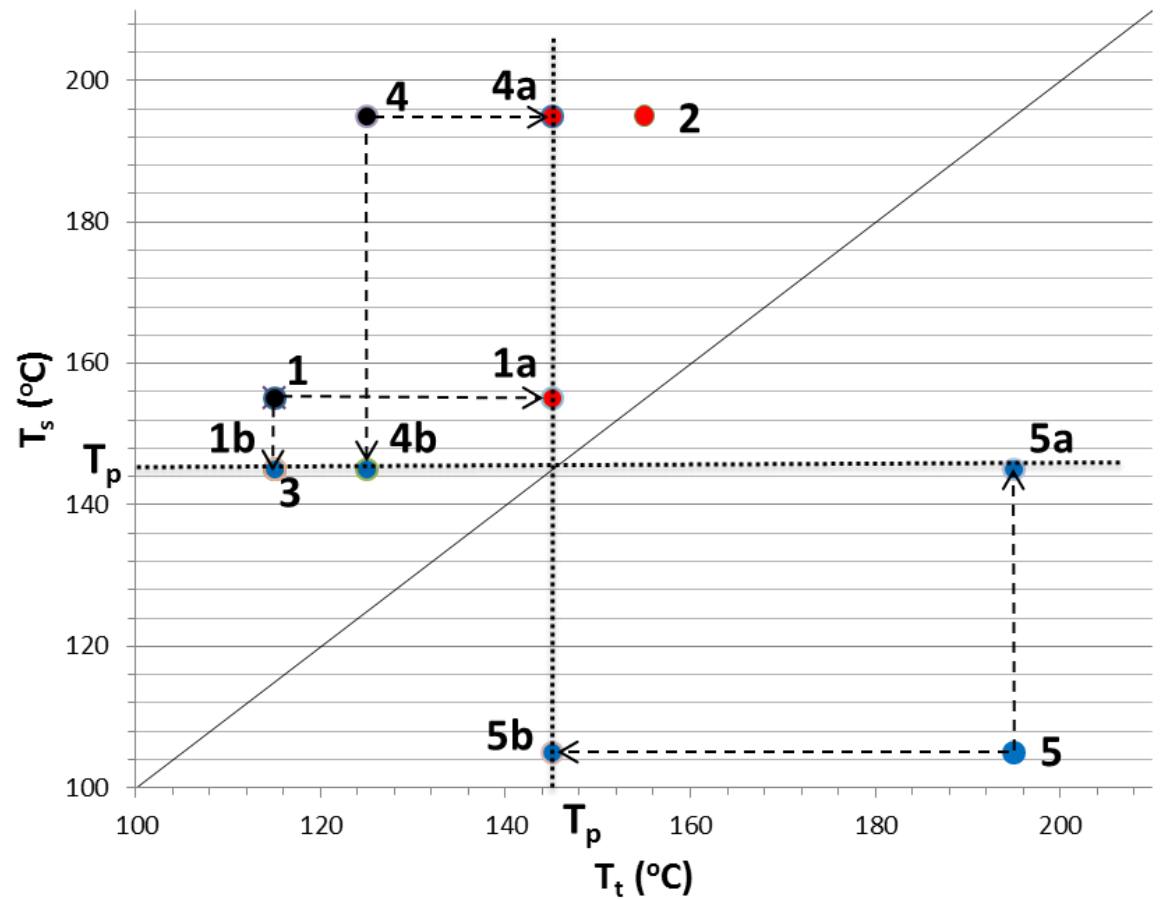

Figure 10. ST-D of the case study

\section{Above the pinch design}

1. Figure 10 represents the ST-D of the process streams given in Table 1. It can be seen that streams (1), (4), and (5) lies in regions 5 and 2 of the ST-D respectively which means that they are cross pinch. Therefore, they need to be divided into their above and below pinch components (1a), (1b), (4a), (4b), (5a), and (5b) respectively, as previously explained in the design algorithm, see Figure 9.

2. Above the pinch, the available heating loads in hot streams are used to satisfy the total or part of the heat required by cold streams.

3. Investigation the streams above the pinch shows that the hot stream (1a) is the closest hot streams to the pinch line; therefore, it is matched first. On the other hand, only one cold stream (5a) is available above the pinch. Therefore, stream (1a) is used to satisfy part of the heat required by stream (5a).

4. Furthermore, Figure 11 shows that target temperatures of both hot streams (1a) and (4a) lie on the pinch line. On the other hand, maximum heat load can be supplied to stream (5a) with target temperature of $\mathrm{T}_{\mathrm{p}}$ is $40 \mathrm{MW}$. Therefore, hot stream (1a) is used to satisfy heat lead of $5 \mathrm{MW}$ required by cold stream (5a1) while hot stream (4a2) is used to supply heat load of $35 \mathrm{MW}$ of cold stream (5a1*).

5. Stream 5a is divided into (5a1), (5a1*), and (5a2) with heat load of (5), (35) and (160) MW respectively, as 
shown in Table 2.

6. Stream (5a1) is connected to stream (1a), see Figure 11.

7. Stream (4a) is divided into (4a1) and (4a2) with heat loads of 15 and 35 MW respectively.

8. Stream $(5 \mathrm{a} 1 *)$ is connected to stream $(4 \mathrm{a} 2)$.

9. The next closer hot stream to pinch line is stream (2) with heat load of $20 \mathrm{MW}$. This heat load is supplied to part of the heat load required by cold stream (5a2). For this purpose, Stream (5a2) is divided into streams (5a21) and (5a22) with heat loads of 20, and 140 MW respectively.

10. Hot stream (2) is connected to cold stream (5a21).

11. The last hot stream (4a1) is connected to part of the heat load of stream (5a22).

12. Stream (5a22) is divided into two streams, (5a221), and (5a222) with heat loads of 15 and $125 \mathrm{MW}$ respectively.

13. Stream (4a1) is connected to stream (5a221).

14. The remaining heat load required by cold stream (5a222) is $125 \mathrm{MW}$ which is the minimum heating utility.

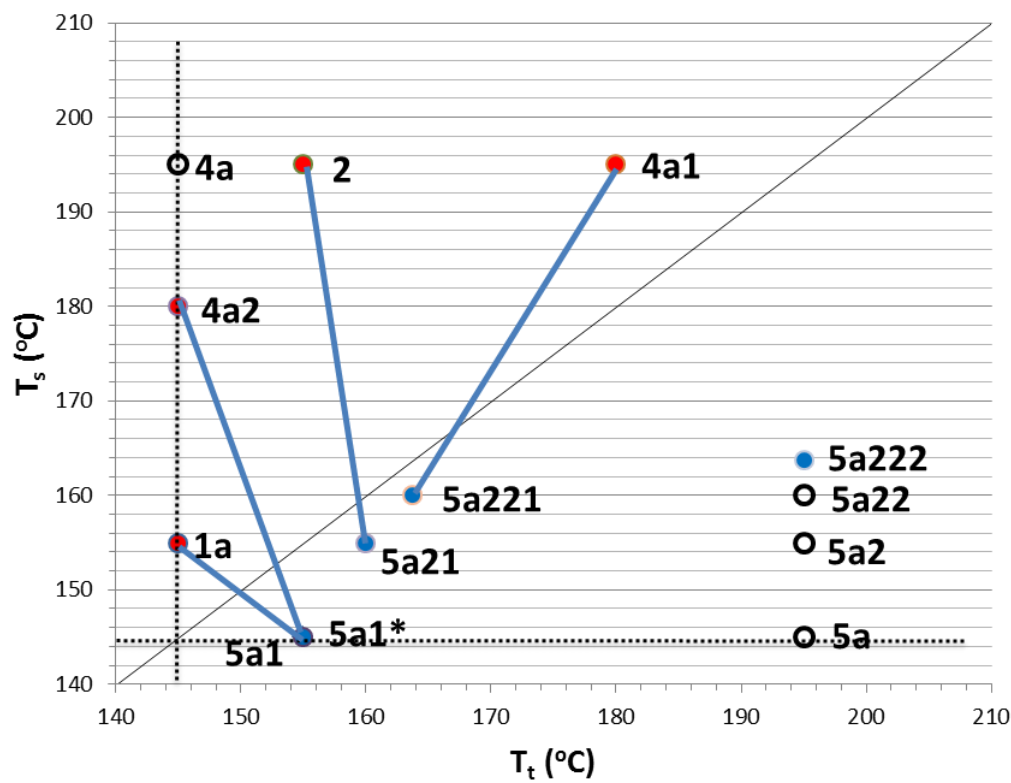

Figure 11. Above the pinch design

Table 2. Above pinch heat exchangers

\begin{tabular}{|c|c|c|c|c|c|c|c|}
\hline $\begin{array}{c}\text { hot } \\
\text { stream }\end{array}$ & TSH & $\mathbf{T}_{\text {TH }}$ & $\mathbf{Q H}_{\mathbf{H}}$ & $\begin{array}{c}\text { Cold } \\
\text { stream }\end{array}$ & $\mathbf{T}$ SC & T & QC \\
\hline & & & & 5 & 105 & 195 & 360 \\
\hline $1 \mathrm{a}$ & 155 & 145 & 5 & $5 \mathrm{a} 1$ & 145 & 155 & 5 \\
\hline $4 \mathrm{a} 2$ & 180 & 145 & 35 & $5 \mathrm{a}{ }^{*}$ & 145 & 155 & 35 \\
\hline & & & & $5 \mathrm{a} 2$ & 155 & 195 & 160 \\
\hline 2 & 195 & 155 & 20 & $5 \mathrm{a} 21$ & 155 & 160 & 20 \\
\hline $4 \mathrm{a}$ & 195 & 145 & 50 & $5 \mathrm{a} 22$ & 160 & 195 & 140 \\
\hline $4 \mathrm{a} 1$ & 195 & 180 & 15 & $5 \mathrm{a} 221$ & 160 & 163.75 & 15 \\
\hline & & & & $5 \mathrm{a} 222$ & 163.75 & 195 & $\mathbf{1 2 5}=\mathbf{Q H}_{\text {Hmin }}$ \\
\hline
\end{tabular}




\section{Below the pinch design}

1. Figure 12 shows the design of HEN below the pinch. The Figure shows three main hot streams, (3), (1b), and (4b) and one cold stream, (5b).

2. Below the pinch, all heat load required by the cold streams are satisfied by the total or part of the heat load available from hot streams below the pinch.

3. The hot stream (4b) is the closest hot stream to the pinch line, therefore, it is matched first.

4. Both streams (3) and (1b) are on the same distance from the pinch. However, the heat load of (1b) is lower than heat load of stream (3). Therefore, stream (1b) is matched first. See Figure 12.

5. Stream (5b) is then divided into three components, (5b1), (5b2) and (5b3) with heat loads of 20,15 and $125 \mathrm{MW}$ respectively, as shown in Table 3.

6. Stream (4b) is connected to stream (5b1), and then stream (1b) is connected to stream (5b2). See Figure 12.

7. The remaining heat load required by the cold stream $(5 \mathrm{~b} 3)$ is $125 \mathrm{MW}$ which is lower than the heat load available from the hot stream (3).

8. Therefore, stream (3) is divided into two components, (3b1) and (3b2) with heat capacity of 125 and $15 \mathrm{MW}$ respectively.

9. Stream (3b1) is connected to stream (5b3) as shown in Figure 12.

10. The heat load of the remaining hot stream ( $3 \mathrm{~b} 2$ ) is $15 \mathrm{MW}$ which is the minimum cooling utility.

Figure 13 shows the complete design of the HEN with a total of 7 heat exchangers, four heat exchangers above the pinch and 3 heat exchangers below the pinch in addition to one heater and one cooler with duties of 125 and $15 \mathrm{MW}$ respectively. The heating and cooling utilities achieved by ST-D meet the energy targets determined by pinch analysis of the process streams [26].

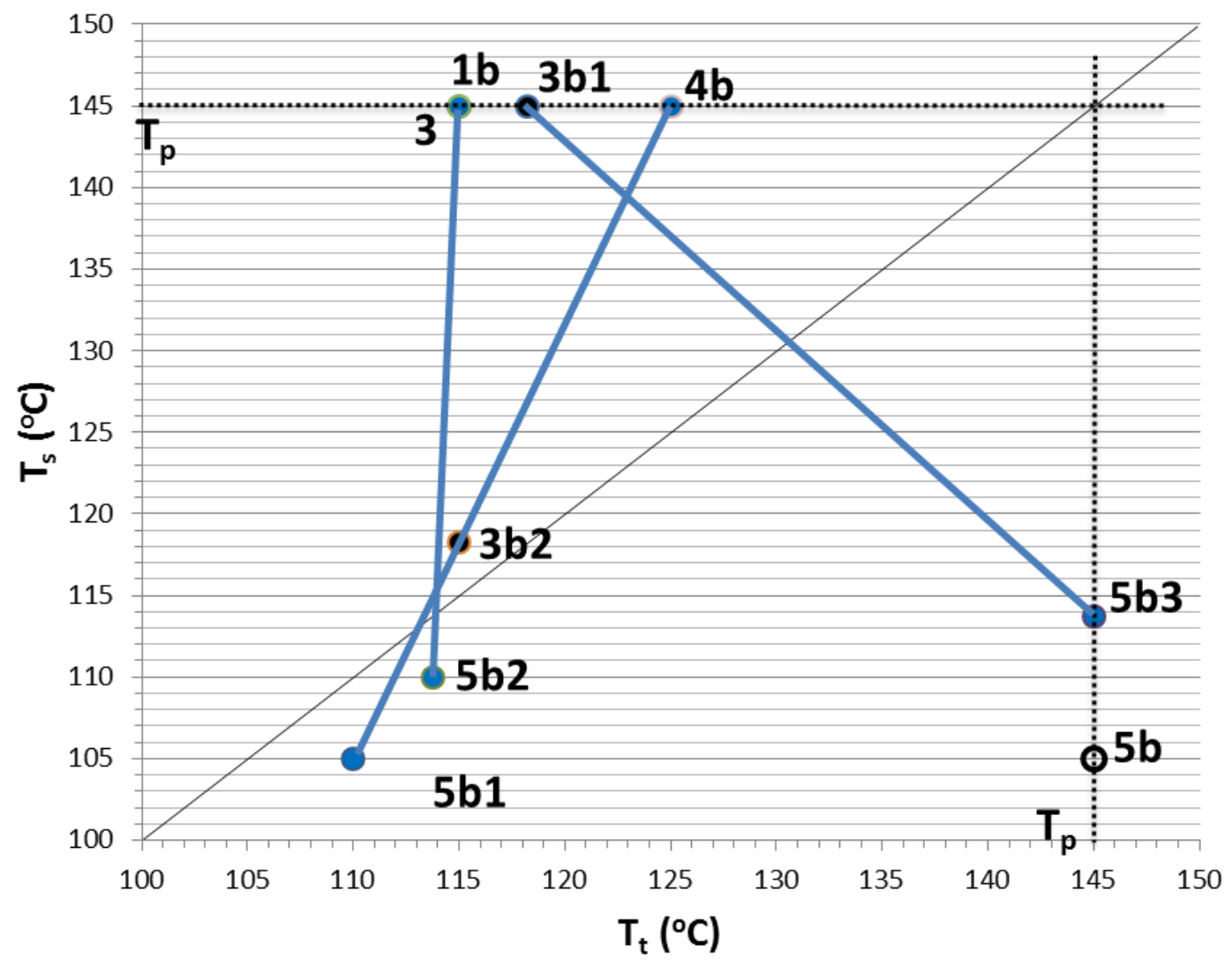

Figure 12. Below the pinch design

Figure 14 shows the grid diagram representation of the complete design of the HEN. The ST-D representation shows 
some advantages over the grid diagram representation, that:

- The ST-D represents a convenient graphical tool.

- Straightforward determination of the intermediate temperatures between exchangers.

- Matching process of streams is easily conducted below and above the pinch point.

- Streams'splitting is immediately evaluated and implemented.

- Cross pinch matching can conveniently be determined and visualized.

- Temperature difference violation can easily be examined and avoided.

In conclusion, ST-D is a useful graphical tool for synthesising and representation of heat exchanger networks toward maximum energy recovery and minimum utilities consumption.

Table 3. Below pinch heat exchangers

\begin{tabular}{|c|c|c|c|c|c|c|c|}
\hline $\begin{array}{c}\text { hot } \\
\text { stream }\end{array}$ & $\mathbf{T}_{\text {SH }}$ & $\mathbf{T}_{\text {TH }}$ & $\mathbf{Q}_{\mathbf{H}}$ & $\begin{array}{c}\text { Cold } \\
\text { stream }\end{array}$ & $\mathbf{T s C}_{\text {sc }}$ & $\mathbf{T}_{\text {TC }}$ & $\mathbf{Q C}_{\mathrm{C}}$ \\
\hline & & & & $5 b$ & 105 & 145 & 160 \\
\hline $1 \mathrm{~b}$ & 145 & 115 & 15 & $5 \mathrm{~b} 2$ & 110 & 113.75 & 15 \\
\hline 3 & 145 & 115 & 140 & & & & \\
\hline $3 \mathrm{~b} 1$ & 145 & 118.21 & 125 & $5 b 3$ & 113.75 & 145 & 125 \\
\hline $3 b 2$ & 118.21 & 115 & $15=Q_{C \min }$ & & & & \\
\hline $4 \mathrm{~b}$ & 145 & 125 & 20 & $5 \mathrm{~b} 1$ & 105 & 110 & 20 \\
\hline
\end{tabular}

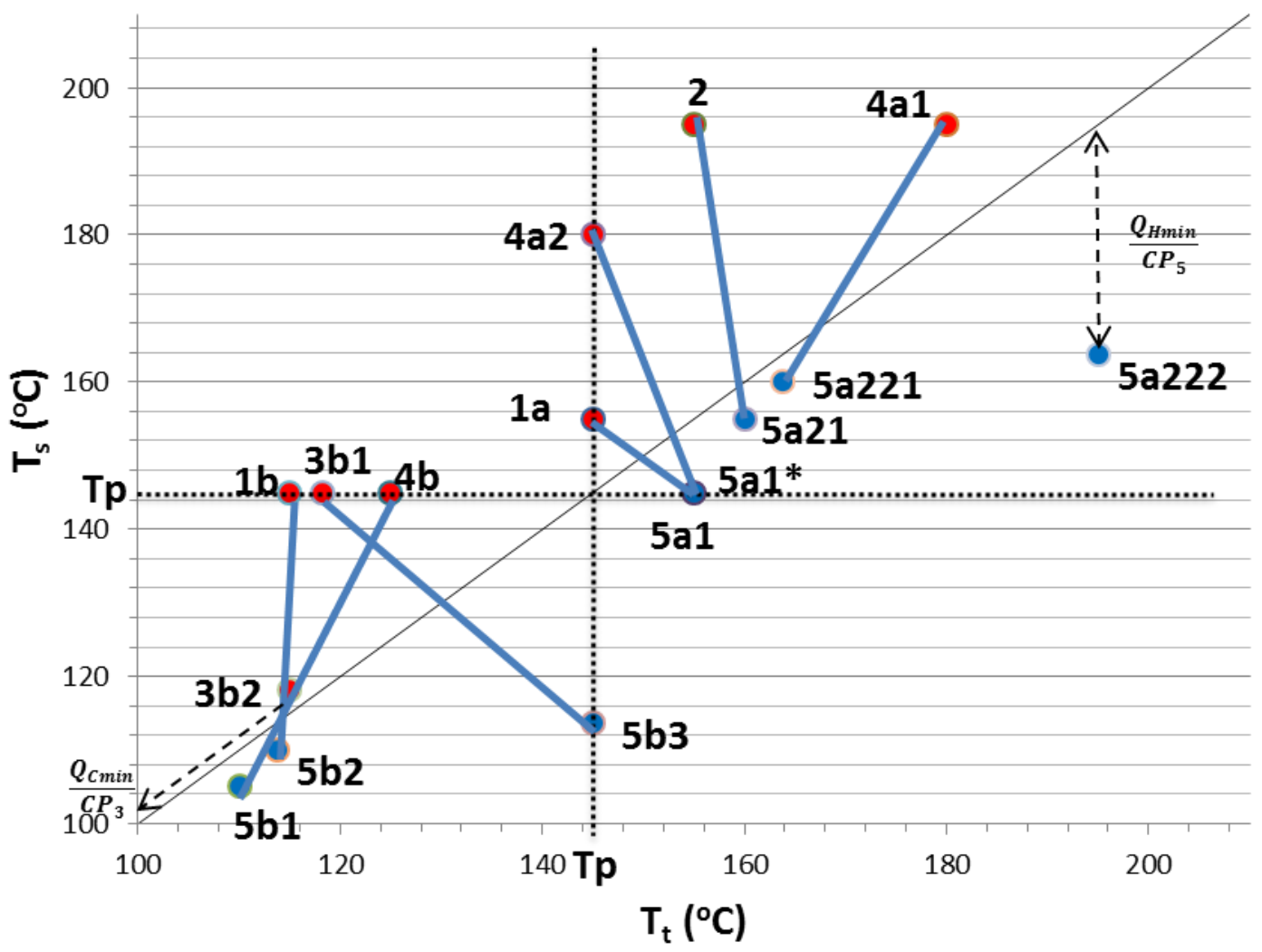

Figure 13. The ST-D representation of the complete HEN design 


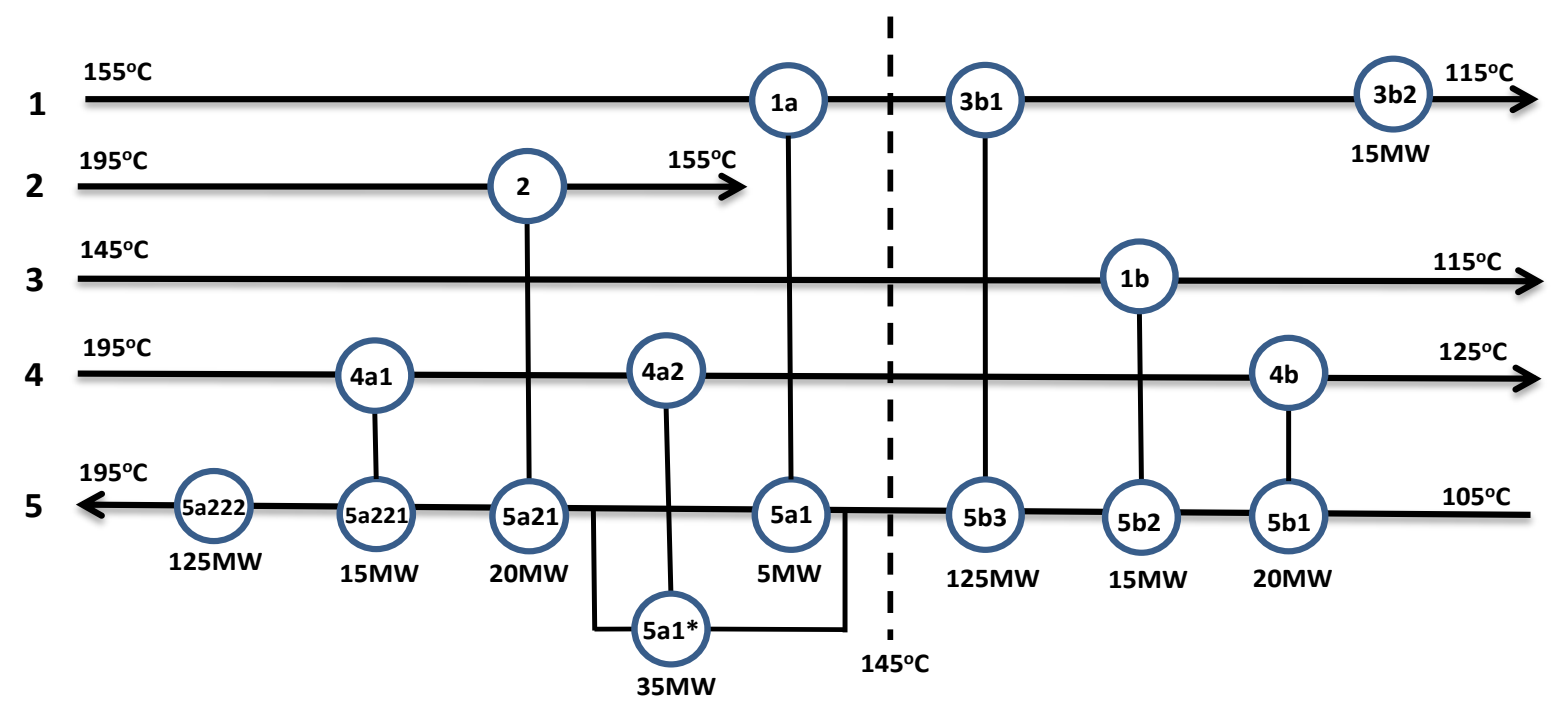

Figure 14. The Grid diagram representation of the complete HEN design

\section{CONCLUSION}

This paper presents a new and simple graphical method for grassroots design of HENs using the SupplyTarget Diagram (ST-D). The ST-D is formulated by plotting streams' supply temperatures versus target temperatures. Streams matching can be easily represented in the ST-D and streams splitting is easily determined and conveniently applied. A systematic procedure for HENs design has been provided based on the principles of pinch analysis. A case study is used to illustrate the application of the new graphical method for grassroots design of HENs. The application of the new graphical method shows that the new method can be successfully used in the designing of new HENs for maximum energy efficiency.

\section{NOMENCLATURE}

$Q_{H} \quad$ Heat load of a hot stream (MW)

$Q_{C} \quad$ Heat load of a cold stream (MW)

$Q_{C \min } \quad$ Minimum cooling duty (MW)

$Q_{\text {Hmin }} \quad$ Minimum heating utility (MW)

$T_{s} \quad$ Supply temperature $\left({ }^{\circ} \mathrm{C}\right)$

$T_{t} \quad$ Target temperature $\left({ }^{\circ} \mathrm{C}\right)$

$T_{P} \quad$ Pinch temperature $\left({ }^{\circ} \mathrm{C}\right)$

$T_{T H} \quad$ Target temperature of a hot stream $\left({ }^{\circ} \mathrm{C}\right)$

$T_{S H} \quad$ Supply temperature of a hot stream $\left({ }^{\circ} \mathrm{C}\right)$

$T_{T C} \quad$ Target temperature of a cold stream $\left({ }^{\circ} \mathrm{C}\right)$

$T_{S C} \quad$ Supply temperature of a cold stream $\left({ }^{\circ} \mathrm{C}\right)$

$C P_{H} \quad$ Heat capacity rate of a hot stream $\left(\mathrm{MW} /{ }^{\circ} \mathrm{C}\right)$

$C P_{C} \quad$ Heat capacity rate of a cold stream $\left(\mathrm{MW} /{ }^{\circ} \mathrm{C}\right)$

\section{REFERENCES}


[2] Litman T. Efficient vehicles versus efficient transportation. Comparing transportation energy conservation strategies. Transport Policy, 2005;12(2):121-129.

[3] Hoseinzadeh S, Hadi Zakeri M, Shirkhani A, Chamkha AJ. Analysis of energy consumption improvements of a zero-energy building in a humid mountainous area. Journal of Renewable and Sustainable Energy, 2019;11: 015103.

[4] Belzer, DB. Energy efficiency potential inexisting potential buldings; Review of selected recent studies. Pacific Northwest National Laboratories, US department of Energy, 2009.

[5] Abdelaziz EA, Saidur R, Mekhilef S. A review on energy saving strategies in industrial sector. Renewable and Sustainable Energy Reviews, 2011;15(1):150-168.

[6] Hoseinzadeh S, Azadi R. Simulation and optimization of a solar-assisted heating and cooling system for a house in Northern of Iran. Journal of Renewable and Sustainable Energy. 2017;9:045101.

[7] IEA 2019, France, Energy Efficiency: Industry: The global exchange for energy efficiency policies, data and impacts, Last Accessed 26 July 2019, https://www.iea.org/topics/energyefficiency/industry/.

[8] Umeda T, Itoh J, Shiroko K. Heat exchange system synthesis. Chemical Engineering Progress, 1978;73(7): 70-76.

[9] Linnhoff B, Flower JR. Synthesis of heat exchanger networks - 1. Systematic generation of energy optimal networks. AIChE Journal, 1978;24(4): 633-642.

[10] Shenoy UV. Heat Exchanger Network Synthesis: Process Optimization by Energy and Resource Analysis. Gulf Publishing Co., Houston, TX, USA, 1995.

[11] Semra O, Salih D. Application for pinch design of heat exchanger networks by use of a computer code employing an improved problem algorithm table. Energy conversion and management, 2001;42:2043-2051.

[12] Smith, R. Chemical Process Design and Integration. John Wiley \& Sons Ltd, West Sussex, UK, 2005.

[13] Klemes J, Friedler F, Bulatov I, Varbanov P. Sustainability in the Process Industry. Integration and Optimization. McGraw-Hill, New York, US, 2010.

[14] Anantharaman R, Nastad I, Nygreen B, Gundersen T. The sequential framework for heat exchanger network synthesis-The minimum number of units sub-problem. Computers and Chemical Engineering 2010;34: 1822-1830.

[15] Boland D, Linnhoff B. The preliminary design of networks for heat exchange by systematic methods. Chem. Eng., 1979; 222.

[16] Yong JY, Varbanov PS, Klemeš JJ. Matrix representation of the grid diagram for heat exchanger networks. Chemical Engineering Transactions, 2015;45:103-108.

[17] Lakshmanan R, Bañares-Alcántara R. A Novel Visualization Tool for Heat Exchanger Network Retrofit, Ind. Eng. Chem. Res., 1996; 35:4507-4522.

[18] Nordman R, Berntsson T. New Pinch Technology Based HEN Analysis Methodologies for Cost-Effective Retrofitting. Can. J. Chem. Eng., 2001; 79(4):655-662.

[19] Osman A, Abdul Mutalib MI, Shuhaimi M, Amminudin KA. Paths combination for HENs retrofit. Applied Thermal Engineering, 2009; 29(14-15):3103-3109.

[20] Wan Alwi SR, Manan ZA. STEP - A new graphical tool for simultaneous targeting and design of a heat exchanger network. Chemical Engineering Journal, 2010;162:106-121.

[21] Abbood NK, Manan ZA, Wan Alwi SR. A combined numerical and visualization tool for utility targeting and heat exchanger network retrofitting. Journal of Cleaner Production, 2012; 23:1-7.

[22] Gadalla MA. A New Graphical Method for Pinch Analysis and Energy Integration. Chemical Engineering Transactions, 2015;43:1291-1296.

[23] Lai YQ, Manan ZA, Wan Alwi SR. Heat Exchanger Network Retrofit Using Individual Stream Temperature vs Enthalpy Plot. Chemical Engineering Transactions, 2017; 61:1651-1656.

[24] Yeo YS, Wan Alwi SR, Ahmad S, Manan ZA, Zamzuri NH. A new graphical method for heat exchanger network design involving phase changes. Chemical Engineering Transactions, 2017; 56:1249-1254.

[25] Al-Mayyahi MA, Albadran FA, Fares MN. Retrofitting Design of Heat Exchanger Networks Using SupplyTarget Diagram. Chemical Engineering Transactions, 2019; 75:625-630. 
Journal of Thermal Engineering, Research Article, Vol.7, No.4, pp. 890-903, May, 2021

[26] Asante NDK, Zhu XX. An automated and interactive approach for heat exchanger network retrofit. Trans IChemE, 1997; 75:349.

[27] Doğan B, Erbay LB. Experimental analysis of the effect of cold fluid inlet temperature on the thermal performance of a heat exchanger. Journal of Thermal Engineering, 1997; 2(1):583-592.

[28] Pourfayaz F, Kasaeian A, Fard MM. A proper selection of hot and cold utilities in a plant containing multiple heat exchanger networks. Journal of Thermal Engineering, 2019; 5(4):341-354. 